\title{
Noise pollution analysis in Tehran cement plant
}

\author{
Ahmadi Orkomi A, $\mathrm{PhD}^{1 *}$, Tavakoli B, $\mathrm{PhD}^{2}$, Noorpoor $\mathrm{A}, \mathrm{PhD}^{3}$ \\ 1- PhD Student, Faculty of Environment, University of Tehran, Tehran, Iran. 2- Assistant Prof., Faculty of Natural \\ Resources, University of Guilan, Rasht, Iran. 3- Associate Prof., Faculty of Environment, University of Tehran, Tehran, \\ Iran.
}

\begin{abstract}
Received: August 2013, Accepted: February 2014

Background: Cement industry has many process units. Basically all of these units can be considered as a source of noise. Since noise pollution is defined based on its offensive hearing effects, the importance of the noise sources depends directly on the number of workers in the unit.

Materials and Methods: An experimental study has been done at Tehran cement factory to recognize and analyze the major noise pollution source machineries. In this survey, first, the mean A-weighted sound pressure level and the number of workers in each unit have been measured and the obtained data has been analyzed in Microsoft Excel. Afterwards, based on the mentioned ISO, some experiments have been done to calculate the A-weighted acoustic power level of the crusher which emits the highest level of noise.

Results: The noisiest units have been recognized and some applicable suggestions have been offered to reduce the sound exposure level. Also by calculating the sound power levels and considering the design parameters which affect the sound power generated by the crusher, an empirical equation has been presented to calculate the acoustic power level as a function of horsepower, number of hammers and the weight of each hammer.

Conclusion: The acoustic measurement results show that the crusher, cement mill and row mill units are the three major noise emission sources. In another experiment, based on ANSI S1.36 and ISO 3746 guidelines, the sound power level of the crusher unit has been measured indirectly. Afterwards, by using a multiple regression algorithm and minimizing the mean square error, an empirical equation has been proposed to correlate the acoustic power level as a function of the horsepower and the mass of all hammers of the crusher.
\end{abstract}

Keywords: Sound, Measurement, Cement

\section{Introduction}

Noise is one of the physical environmental factors affecting human health. Because of the adverse effects on people's, life in the large and industrial cities, noise pollution is becoming a remarkable concern. Noise in work environment is the major cause of concern for safety and health of the factory workers. Regulations limiting the noise exposure of industrial workers have been instituted in different countries $(1,2)$. The aim of these noise regulations is to ensure that workers' hearing is protected from excessive noise at their place of work, which could cause them to lose their hearingor to suffer from tinnitus. Noise in work environment is the major cause of concern for safety and health of the factory workers. Industrial laws in many countries provide protection for workers against noise pollution as described by the National Environmental Standards Committee of the Tanzanian Bureau of Standards (TBS) (3).

Exposure duration of $40 \mathrm{hr}$ per week of equivalent noise level of $85 \mathrm{dBA}$ is

* Corresponding author: Ali Ahmadi Orkomi, Faculty of Environment, University of Tehran, Tehran, Iran.

Email: Orkomi@ut.ac.ir 
considered to be safe and noise level above this limit is bound to cause induced temporary or permanent hearing loss (4-6). Cement manufacturing is one of the major areas that play a significant role in economy of countries. Sharma, et.al (7) compared experimental sound pressure level (SPL) with the calculated SPL by proposed formula and related the exposed SPL to the horsepower and the life time of the source. Also some researchers have been done on measuring the noise level in cement plants, analyzing the hearing damage to labors and providing some noise control suggestions to reduce the damaging effects of noise exposure (8-10).With the aim of noise generation parameters recognition, a vast research has been done $(11,12)$. Makarewicz (13) and Jones and Hothersall (14) studied the effective parameters on road vehicle noise generation. The cement production machineries emit offensive noise because they have a high acoustic power. In the design point of view, to investigate the sensitivity of the emitted noise to the physical parameters, the influence of the parameters on the sound power level should be conducted. But based on the writers' knowledge, the effect of design parameters on cement machineries noise emission has not been published well. In this work an experimental survey has been done in Tehran cement plant to demonstrate the most noise emission sources. To overcome the aforementioned drawbacks in recognition the affecting parameters on the acoustic power level, an empirical equation has been presented to correlate the sound power level of the crusher to its design variables. The paper is organized as follows. In the material and methods section, the algorithm of sound pressure level measurement and the formulation to calculate sound power level have been discussed. In the results section, the measurement results have been reported and the noisiest units have been detected. Also, correlation between sound power level and some key effecting parameters has been discussed. Some conclusion remarks have been highlighted in the last section.

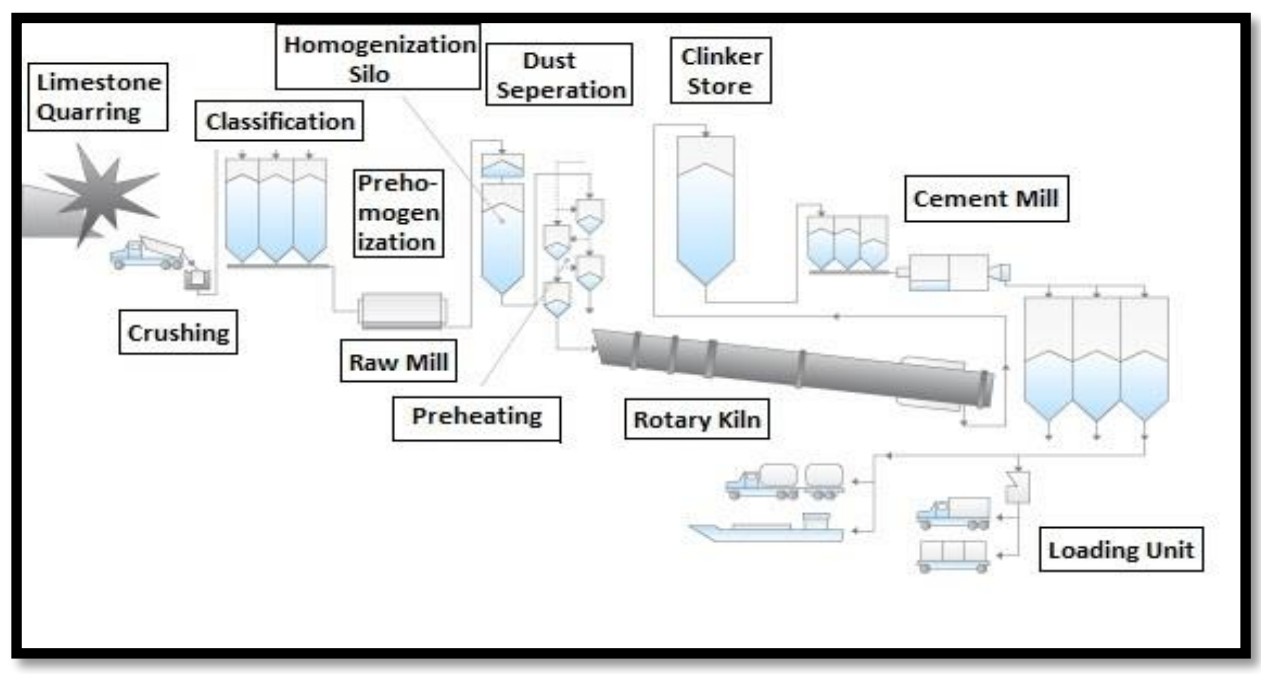

Figure1: Schematic diagram of process units in a cement factory 


\section{Materials and Methods}

This study was conducted at Tehran cement factory. Tehran cement factory is one of the highest ranking cement producers in Iran and its product is type 2 Portland cement. Based on the researcher's knowledge, studies about the noise pollution from machinery and the noise exposure rate in the workers zones have not been well established for this industrial plant. A schematic diagram of the main process units in a cement factory has been shown in Figure 1 and the overall map of the cement plant has been demonstrated in Figure 2. All measurement procedures were according to the ISO 3746 (15) and the noise levels were measured by a digital mini sound pressure level meter (MODEL TES 1353H) in the workers main commuting spots. The measurements have been done during the work hours on July 20, 2013, between 11.00 am and $4.00 \mathrm{pm}$, in which all of the major machines were running and the number of workers was at maximum level.

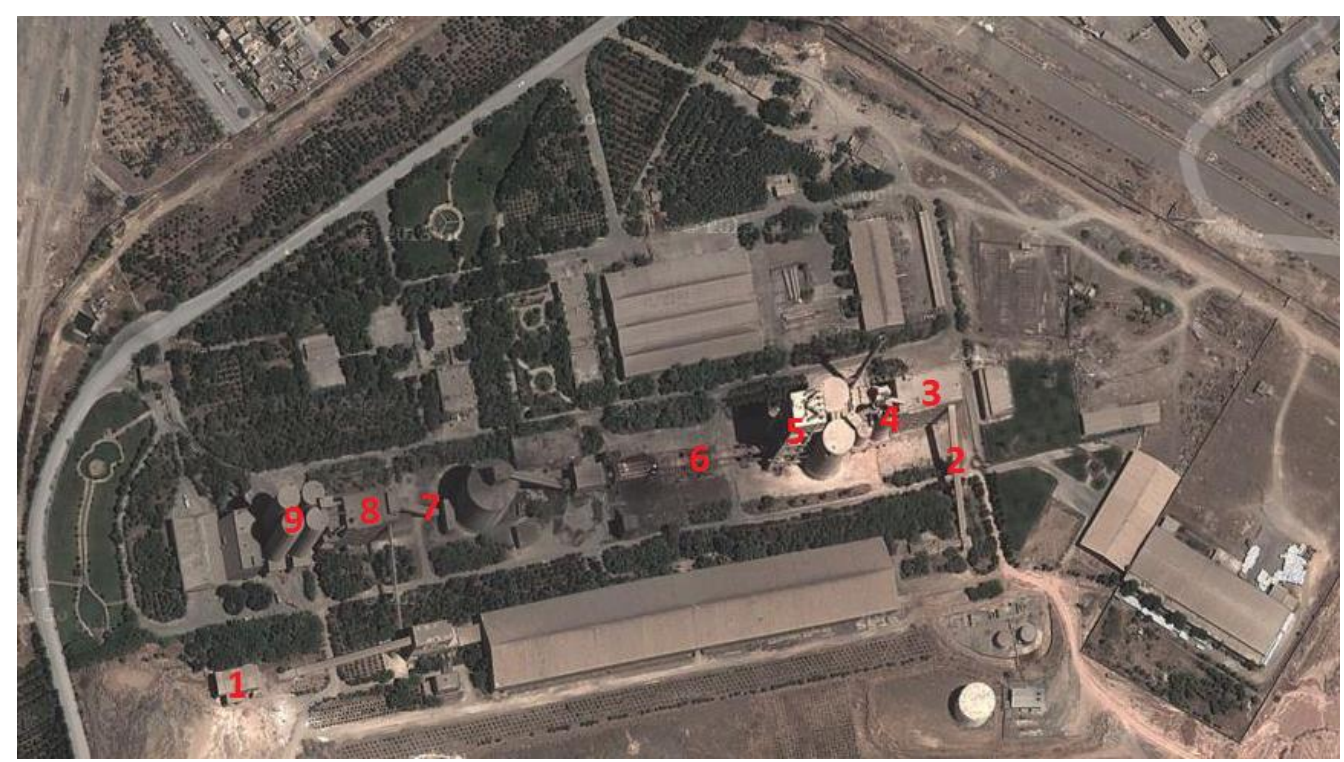

Figure 2: Perspective view of Tehran cement plant with tagged SPL measuring areas

Firstly, the number of units and the measuring areas in each unit have been chosen based on the noted ISO algorithm. The measuring units in the plant are main stone crusher, row material mill, pre heater, kiln, kiln to cement mill conveyer line, cement mill and packing unit. These units also have been tagged in Fig. 2. To obtain a better and more reliable data, for the large areas, the number of measuring point was increased. Some of units in this plant have more than three floors. For example in the row of material mill there is a separate floor for the mill, gearboxes and centrifugal separators. So in such a unit to obtain a remarkable and tangible result, the measurement has been done on all the floors separately. In all the measurement points the sound level meter was set toward the mentioned unit and 60 centimeters away from operator.

The pressure level of a source can be measured directly and easily, but until now, there is not a devise or algorithm to measure the sound power level of an acoustic source directly. The importance of the sound power level has become evident from design and noise control point of view. The pressure 
level of a distinct source depends on the features of the environment in which the sound transmits and it is different for a noise source in two different media. Then the SPL cannot be a sound feature for design purposes. In contrast, the sound power level is only a function of the design and operational parameters of the sound source. So if the value of sound power level is calculated, by correlating the power level with the physical parameters (like power, frequency, size, constructing materials and etc.), a machine with a lower value of emitted sound power level can be designed by altering the affecting parameters.

In this work, an empirical relationship correlates the sound power level of crusher unit to some independent effective physical parameters. In approach to the aforementioned purpose, the value of sound power level was calculated in some different values of independent variables. The sound power level was calculated from SPL data. According to Barron (16), the method of calculation of the sound power level from SPL data depends on the space in which the source is located. If the desired environment is an ideal reverberant or an anechoic room, some national and international standards like ANSI S1.31, ANSI S1.32, ANSI S1.33 and ANSI S1.35 (17-20) and ISO 3741, ISO 3742, ISO 3743 and ISO 3745 (21-24) for measuring the SPL are used. In this work the environment was not an ideal reverberant or anechoic room so for this real room, the survey method established by ANSI S1.36 (25) and ISO 3746 (15), has been applied.

In this work one microphone was used for measurement. According to the survey method, there are nine key measurement points around the source as depicted in figure 3.

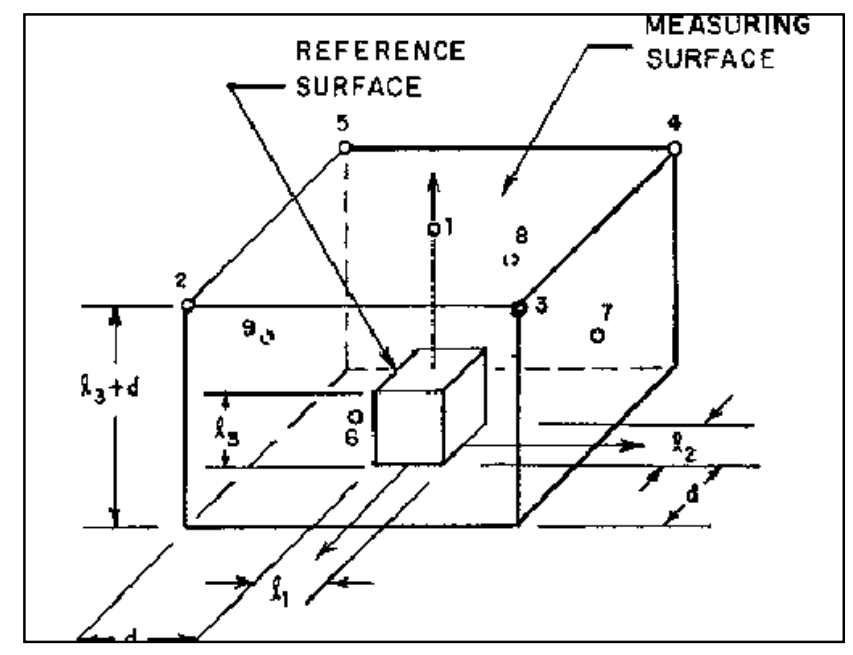

Figure 3: Key measuring points around a noise source in the survey method

According to the survey algorithm described in Barron (16), the values of constants in figure 3 can be selected based on the dimension of the source. The acoustic intensity for a direct and reverberant acoustic energy can be formulated as below,

$\mathrm{W}\left(\frac{4}{\mathrm{R}}+\frac{1}{\mathrm{~S}_{\mathrm{m}}}\right)=\frac{\mathrm{W}}{\mathrm{S}_{\mathrm{m}}}\left(\frac{4 \mathrm{~S}_{\mathrm{m}}}{\mathrm{R}}+1\right)=\frac{\mathrm{P}_{\mathrm{ave}}^{2}}{\rho \mathrm{c}}$ 
where $P_{\text {ave }}$ is the energy averaged sound pressure and is defined as $P_{a v e}^{2}=\sum_{i=1}^{9} P_{i}^{2} / 9$ and $S_{m}$ is the virtual enclosed surface in Fig. 1 and is defined below,

$$
\begin{aligned}
S_{m}=2((l 1+ & 2 d) *(l 2+2 d) \\
& +(l 3+d) \\
& *((l 1+2 d) \\
& +(l 2+2 d)))
\end{aligned}
$$

$R$ is the room constant and may be calculated from Eq. [3].

$$
R=\frac{\bar{\alpha} \cdot S_{0}}{1-\bar{\alpha}}
$$

in which $\bar{\alpha}$ is the average absorption coefficient and $S_{0}$ is the surface area of the space in which the noise source is located. By defining the parameter $K_{r}$ as Eq. [4] and taking the logarithm from both sides of Eq. [1], Eq. [5] can be obtained.

$$
\begin{aligned}
& K_{r}=10 \log _{10}\left[1+\frac{4(1-\bar{\alpha}) S_{m}}{\bar{\alpha} \cdot S_{0}}\right] \\
& L_{W} \\
& =L_{P_{\text {ave }}} \\
& +10 \log _{10}\left(\frac{S_{m}}{S_{\text {ref }}}\right)-K_{r} \\
& -10 \log _{10}\left(\frac{\rho_{0} c W_{\text {ref }}}{P_{\text {ref }}^{2} S_{\text {ref }}}\right), S_{\text {ref }}=1 \mathrm{~m}^{2}
\end{aligned}
$$

For air at standard condition, the last term of Eq. [5] is approximately equal to 0.1 decibel (dB). So by measuring the sound pressure level the sound power level of the noise source can be obtained during each operating condition by applying the Eq. [5]. By these data, the empirical relation between sound power level and the effecting designing and operating parameters can be derived. The major effective parameters which has been considered are the engine power, mass of hammers (mass of one hammer times the number of hammers) and angular velocity (rpm). Four crusher units have been studied in this survey. Three of them were the main stone crushers located in unpainted block rooms. The surface absorption coefficient of such a room is reported as 0.35 in Barron (16). The other crusher was a mini crusher installed between kiln and cement mill units to operate on the clinker particles. It should be noted that the sub crusher is located in an open field in which the reverberant acoustic field is much lower than the direct field. So, this environment can be dealt as an anechoic room and the sound power level calculation procedure is as below,

$$
W=\sum_{j} I_{j} S_{j}=\frac{S_{0} \cdot \sum P_{j}^{2}}{\rho_{0} \cdot C \cdot N_{s}}
$$

Where $j$ is counter on the number of measuring points. The total area of the hemisphere commonly has been divided to $\mathrm{N}_{\mathrm{s}}$ equal surfaces. Here the value of $\mathrm{N}_{\mathrm{s}}$ is selected as 6. $\rho_{0}$ and $C$ are the air mass density and sound velocity in the air in the operating condition (0.98 atm. and $\left.40{ }^{\circ} \mathrm{C}\right)$ respectively. $P_{j}$ is the SPL at point $j$ in Pascal. It should be considered that the SPL of four crusher units has been measured 300 $\mathrm{mm}$ away from the source.

\section{Results}

Regarding to the number of measurement in a unit, the logarithmic average of the data has been obtained and reported as the mean sound pressure level of the unit. The result of all executed measurement has been demonstrated in table 1 . It should be noted that the units' numbers in table 1 and the tagged numbers in figure 2 are identical. 
Table 1: SPL values and the number of labours in noisy units of the cement plant

\begin{tabular}{|c|c|c|c|c|c|c|}
\hline & Unit & $\begin{array}{l}\text { Sample } \\
\text { NO. }\end{array}$ & $\begin{array}{l}\text { Labor } \\
\text { NO. }\end{array}$ & SPL-L $\mathbf{L}_{\text {Aeq }}$ & SPL-max & $\begin{array}{l}\text { SPL- } \\
\text { min }\end{array}$ \\
\hline \multirow{3}{*}{1} & Crusher (Ground) & 14 & \multirow{3}{*}{2} & 102.4 & 105 & 98 \\
\hline & Crusher (Underground-1) & 4 & & 98.9 & 101 & 97 \\
\hline & Crusher (Underground-2) & 2 & & 87 & 88 & 86 \\
\hline 2 & Conveyor (Crusher to Raw Mill) & 4 & 1 & 78.1 & 80 & 76.3 \\
\hline \multirow{4}{*}{3} & $\begin{array}{c}\text { Raw Mill-First Floor (Gearbox } \\
\text { Unit) }\end{array}$ & 16 & \multirow{4}{*}{3} & 99.15 & 103.3 & 93 \\
\hline & Raw Mill-Second Floor & 6 & & 92 & 94.1 & 88 \\
\hline & $\begin{array}{l}\text { Raw Mill-Third Floor } \\
\text { (Separators) }\end{array}$ & 3 & & 82.8 & 83 & 82.5 \\
\hline & $\begin{array}{c}\text { Raw Mill- Fourth Floor (Gearbox } \\
\text { Elevators) }\end{array}$ & 6 & & 87.1 & 88.9 & 86.8 \\
\hline 4 & Raw Mill Blower & 7 & 1 & 98.8 & 101 & 98 \\
\hline 5 & Pre heater & 6 & 8 & 86.2 & 87 & 81 \\
\hline 6 & Kiln & 6 & 1 & 80 & 80.1 & 78 \\
\hline 7 & Conveyor (Kiln to Cement Mill) & 3 & 1 & 81 & 81.5 & 80 \\
\hline \multirow{4}{*}{8} & $\begin{array}{l}\text { Cement Mill - First Floor } \\
\text { (Gearbox Unit) }\end{array}$ & 12 & \multirow{4}{*}{2} & 100.83 & 103.8 & 99.3 \\
\hline & Cement Mill - Second Floor & 4 & & 98.9 & 100 & 98 \\
\hline & Cement Mill - Third Floor & 6 & & 88 & 89 & 85 \\
\hline & $\begin{array}{l}\text { Cement Mill - Fourth } \\
\text { Floor(Separators) }\end{array}$ & 6 & & 84.1 & 85 & 83.3 \\
\hline 9 & Packing Unit & 8 & 16 & 81 & 85 & 79.2 \\
\hline
\end{tabular}

By using the data in table 1 , the most intensive noise emission sources in this factory are summarized in table 2 . According to tables 1 and 2, it can be concluded that the noisiest source is the crusher unit with the mean SPL 102.4 dB at its basement. Among the nine units, the packing unit, kiln to cement mill and crusher to row mill conveyers, kiln and pre heater have the equivalent sound pressure level $\left(\mathrm{L}_{\text {Aeq }}\right)$ lower than $85 \mathrm{~dB}$. So they are acoustically the safe zones for the labors. But in the high noise exposure units (e.g. crusher unit), there is major risk of hearing loss for the operators. Although the workers in these units use hearing protection gears, it is not an efficient control strategy. Because despite using the gears, the workers in these zones, have a sound lever induced hearing damages.

To reduce the level of hearing damages, it is recommended to update the installed control programs or employ part time operators or alter their activity zones between safe and unsafe acoustical zones or apply new control strategies in the noisy zones. The noise emitted from the noted units in Tehran cement factory can be harmful for the people in the surrounding residential zones.

As can be seen in Figure 2, by planting trees around the factory, the noise level has been reduced to a tolerable level at the residential area. As noted in the preceding paragraphs, in this survey, the crusher unit emitted the maximum level of noise in the plant. As can be seen in previous published works $(10,26)$, 
this unit is one of the top ranked noise pollution sources. So regardless of the type of stone in different factories, this unit naturally is a main source of noise. In this regard, it cannot be a rough idea to consider the designing parameters as the main cause of noise emission. So in the following section it has been tried to correlate the emitted noise of the crusher unit to its physical parameters.

Table 2: Most noisy units in Tehran cement factory

\begin{tabular}{l|c}
\multicolumn{1}{c|}{ Unit Name } & $\begin{array}{c}\text { SPL- } \\
\text { LAeq }_{\text {Aeq }}\end{array}$ \\
\hline Crusher (Ground) & 102.4 \\
\hline $\begin{array}{l}\text { Cement Mill - First Floor (Gearbox } \\
\text { Unit) }\end{array}$ & 100.83 \\
\hline Raw Mill-First Floor (Gearbox Unit) & 99.15 \\
\hline Crusher (Underground-1) & 98.9 \\
\hline Cement Mill - Second Floor & 98.9 \\
\hline Raw Mill Blower & 98.8 \\
\hline
\end{tabular}

Based on the equations [1-6], the crusher sound power level has been calculated. Some features of the crushers and the result of power level calculation have been summarized in table 3.To demonstrate the mathematical correlation among the sound power level and the effective parameters, the Eq. [7] has been considered as below,

$$
\begin{gathered}
L_{w}=A+B * \log \left(\frac{h p}{h p_{0}}\right)+C \\
* \log \left(\frac{M_{h}}{M_{h 0}}\right)
\end{gathered}
$$

in which $h p$ and $M_{h}$ are the horsepower of crusher and the mass of hammers respectively. $h p_{0}$ and $M_{h 0}$ are the reference values of the noted parameters which have been set to 1.The angular velocity for all four crushers was $1000 \mathrm{rpm}$. So its effect on $L_{w}$ cannot be considered in this case. The value of constant $A$ in Eq. [7] can be a representative, which implicitly shows the effect of some operating and design parameters, have not been considered here.

\begin{tabular}{|c|c|c|c|c|c|c|c|c|}
\hline Unit & Dimensions & $\begin{array}{c}\text { Hammer } \\
\text { No. }\end{array}$ & $\begin{array}{c}\text { Mass of } \\
\text { Hammer } \\
\text { (kg) }\end{array}$ & $\begin{array}{l}M_{h} \\
(k g)\end{array}$ & $\begin{array}{c}\text { Sample } \\
\text { No. }\end{array}$ & Нp & $\begin{array}{c}\text { Lw } \\
(\mathbf{d B})\end{array}$ & $\begin{array}{c}\text { Room } \\
\text { dimensions }\end{array}$ \\
\hline Stone crusher 1 & $2 * 1 * 2$ & 70 & 75 & 5250 & 9 & 1502 & 111.8 & $8 * 8 * 3$ \\
\hline Stone crusher 2 & $3 * 2 * 3$ & 84 & 120 & 1080 & 9 & 1745 & 117.4 & $10 * 10 * 4$ \\
\hline Stone crusher 3 & $3 * 2 * 2$ & 70 & 90 & 6300 & 9 & 805 & 106.4 & $12 * 6 * 3$ \\
\hline Sub crusher 1 & $2 * 1 * 1$ & 60 & 52 & 3120 & 6 & 422 & 102.3 & - \\
\hline
\end{tabular}

Table 3: Measured sound power level and some parameters of the crushers

By using the data in table 3 and the proposed Eq. [7], a multiple regression algorithm by minimizing the mean square error has been used to calculate the unknown coefficients in Eq. [7]. The unknown coefficients $A, B$ and $C$ in Eq.[7] have been obtained 15, 10 and 17 respectively. By the obtained coefficients, the predicted value of $L_{W}$ has been calculated by Eq. [7] and compared with the measured values in Figure 4.
As it can be seen, there is a reliable consistency between the predicted values by the proposed equation and the measured data. It should be noted that by measuring more data in different factories with diverse types of crushers, the effect of other physical parameters like angular velocity, capacity of the machine and the aspect ratio of stone can be highlighted. This plan is one of our next goals in this research area. 


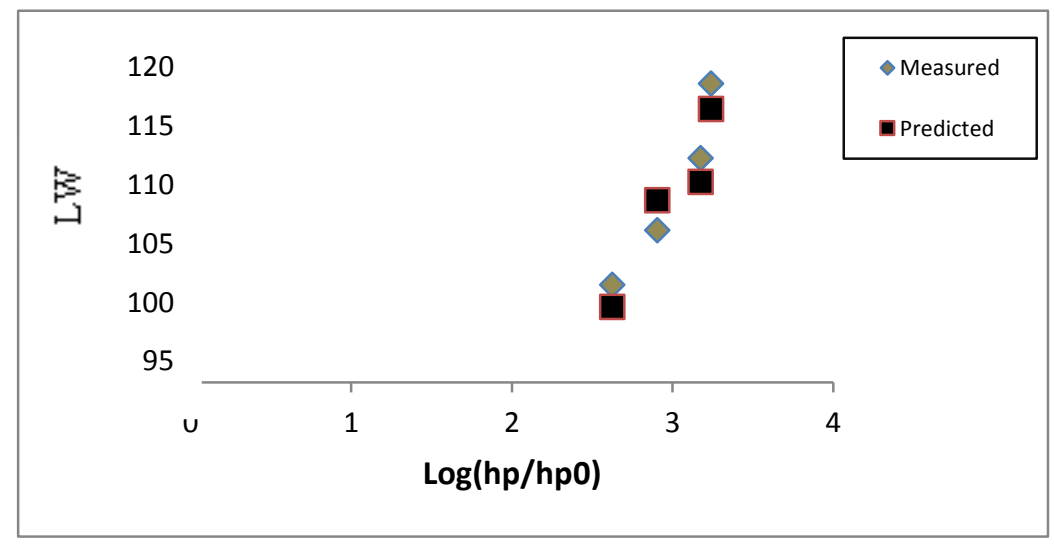

Figure 4.a: Measured and predicted values of $L W$ versus horsepower.

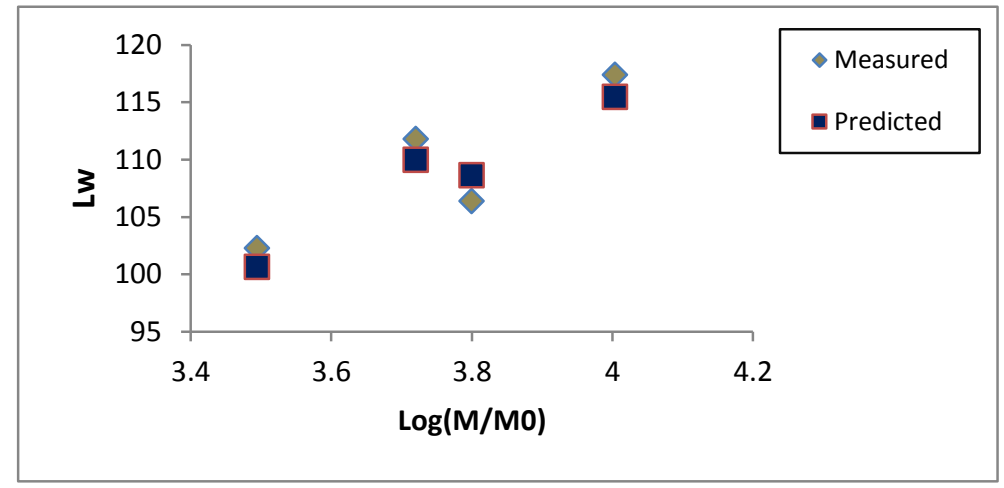

Figure 4.b: Measured and predicted values of Lw versus total hammers' mass

\section{Discussion}

In the present study the noise pollution problem in the unit No.7 of Tehran cement company has been addressed. The acoustic measurement results show that the crusher

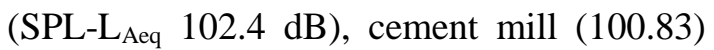
and row mill (99.15) units are the three major noise emission sources and the packing unit, kiln to cement mill and crusher to row mill conveyers, kiln and pre heater are acoustically the safe zones for the laborers. After that, the crusher unit as the noisiest unit in the cement plant has been studied separately to identify the physical and operational parameters affecting the noise level of the equipment. By using a multiple regression algorithm and minimizing the mean square error, an empirical equation has been proposed to correlate the acoustic power level as a function of the horsepower and the mass of all hammers of the crusher. Although, the number of crushers which have been studied in this study is relatively low. Our next aim is to study crushers in Guilan cement factory and modify the functionality between noise level and physical properties.

\section{Conclusion}

In this work a survey analysis has been done in Tehran cement factory to find the noisiest sources which emit the noise in workers main commuting spots. It is recommended to 
update the installed control programs in the factory to protect the workers from the harmful levels of noise pollution. The SPL depends on the features of the environment in which the sound transmitted, while the sound power level is only a function of the design and operational parameters of the sound source. So by calculating the sound power level and finding its functionality with the physical parameters (like power, frequency, size, constructing materials and etc.), a machine with a lower value of emitted sound power level can be designed by altering the affecting parameters. Because of the mentioned reason, in another experiment, based on the ANSI S1.36 and ISO 3746 guidelines, the sound power level of the crusher unit has been measured indirectly. Finally an empirical equation which correlates the sound power level with the physical parameters has been obtained.

\section{Acknowledgements}

The authors would like to thank the staffs and managers of Tehran cement company for their cooperation and useful guidance.

\section{Conflict of Interest: Non declared}

\section{References}

1. Eleftheriou PC. Industrial noise and its effects on human hearing. Applied Acoustics 2002; 63(1):35-42.

2. Tanzania Bureau of Standards (TBS). ACOUSTICS - General Tolerance Limits for Environmental Noise, National Environmental Standards Compendium. EMDC 2005. 6(2):1733.

3. S.I 2005/ 1643. The Control of Noise at Work Regulations 2005. Health and safety, UK.
4. National Institute for Occupational Safety and Health (NIOSH). Criteria for a recommended standard: Occupational noise exposure Revised Criteria 1998. U.S. Department of Health and Human Services, Center for Disease Control and Prevention, Cincinnati, Ohio. June 1998.

5. Melamed S, Fried Y, Froom P. The interactive effect of chronic exposure to noise and job complexity on changes in blood pressure and job satisfaction: A longitudinal study of industrial employees. J Occup Health Psychol 2001; 6(3):182-95.

6. Rick N. Noise exposure standards around the world. Washington: Department of Environmental and Occupational Health Sciences, University of Washington; 2004.

7. Sharma O, Mohanan V, Singh M. Noise emission levels in coal industry. Applied Acoustics 1998; 54(1):1-7.

8. Canfeng Z, Shujie Y, Dong L (2012). Comprehensive control of the noise occupational hazard in cement plant. Procedia Engineering 2012; (43):186-90.

9. Asdrubali F, Baldinelli G. Acoustic impact evaluation and mitigation of cement production plants. Presented at the $32 \mathrm{nd}$ international congress and exposition on noise control engineering jeju international convention center, Seogwipo, Korea, August 25-28, 2003. pp. 25-28.

10. GhotbiRavandi MR, Nadri F, Khanjani N, Ahmadian M. Occupational noise exposure among the workers of Kerman cement plant, 2009. J Occu Health Epidemiol 2012; $1(1): 17-23$.

11. Heitner I. How to estimate plant noises. Hydrocarb. Process 1968; 47:67-74.

12. Ellis RM. Cooling tower noise generation and radiation. J Sound Vib 1971; 14(2):17182.

13. Makarewicz R. Generation parameter of a road vehicle. Applied Acoustics 2012; 73(67):610-13.

14. Jones R, Hothersall D. Effect of operating parameters on noise emission from individual road vehicles. Applied Acoustics 1980; 13(2):121-36.

15. ISO 3746:1995. Acoustics-determination of sound power levels of noise sources using sound pressure-survey method using an enveloping measurement surface over a reflecting plane. International Organization for Standardization, Geneva, Switzerland. 
16. Barron RF (2001). Industrial Noise Control and Acoustics. New York: Marcel Dekker.

17. ANSI S1.31-1980. Precision methods for the determination of sound power levels of broad-band noise sources in reverberation rooms. Acoustical Society of America, Woodbury. ( see ASA 11-80)

18. ANSI S1.32- 1980. Precision methods for the determination of sound power levels of discrete frequency and narrow-band noise sources in reverberation rooms. Acoustical Society of America, Woodbury. ( see ASA 12-80)

19. ANSI S1.33-1982. Engineering methods for the determination of sound power levels of noise sources in a special reverberation test room. Acoustical Society of America, Woodbury. ( see ASA 13-82)

20. ANSI S1.35-1979. Precision methods for the determination of sound power levels of noise sources in anechoic and hemi-anechoic rooms. Acoustical Society of America, Woodbury. ( see ASA 15-79)

21. ISO 3741:1988. Acoustics-determination of sound power levels of noise sourcesPrecision methods for broad-band sources in reverberation rooms. International Organization for Standardization, Geneva,
Switzerland.

22. ISO 3742:1988. Acoustics-determination of sound power levels of noise sourcesPrecision methods for discrete-frequency and narrow-band sources in reverberation rooms. International Organization for Standardization, Geneva, Switzerland.

23. ISO 3743: 1994. Acoustics-determination of sound power levels of noise sources-using sound pressure-Engineering methods for small, movable sources in reverberant fieldsPart 2: Methods for special reverberation test rooms. International Organization for Standardization, Geneva, Switzerland.

24. ISO 3745:1977. Acoustics-determination of sound power levels of noise sourcesPrecision methods for anechoic and semianechoic rooms. International Organization for Standardization, Geneva, Switzerland.

25. ANSI S1.36-1979. Survey methods for determination of sound power levels of noise sources. Acoustical Society of America, Woodbury.( see ASA 16-79)

26. Mndeme FG, Mkoma SL. Assesment of work zone noise levels at a cement factory in Tanga Tanzania. The Ethiopian Journal of Environmental Studies and Management 2012; 5(3):225-31. 